\title{
DIMENSÕES DA ALTERIDADE EM AUTOBIOGRAFIAS ESPIRITUAIS FEMININAS EM PORTUGAL (SÉCULOS XVII-XVIII)
}

ANABELA GALHARDO COUTO

IADE- Instituto universitário de Artes Visuais, Design e Marketing Universidade Aberta anabela.couto@iade.pt

RESUMO: Este artigo centra-se em algumas narrativas autobiográficas de índole espiritual escritas por monjas no Portugal de seiscentos. Especial atenção é conferida à narrativa do eu amoroso, à descrição dos êxtases e visões extraordinárias que estas narrativas comportam. Partindo das propostas de Michel de Certeau e também de Luisa Muraro nos seus trabalhos dedicados à escrita mística, trata-se de perceber até que ponto esses textos portugueses de autoria feminina oferecem a possibilidade de pensar e articular diferentes espaços discursivos, configurando um discurso aberto à alteridade.

PALAVRAS-CHAVE: Literatura de autoria feminina; literatura barroca de língua portuguesa; autobiografias espirituais; alteridade. 


\section{PORTUGUESE WOMEN'S SPIRITUAL AUTOBIOGRAPHIES (SEVENTEENTH AND EIGHTEENTH CENTURIES): Spaces of Al- terity}

ABSTRACT: This paper explores the spiritual autobiographies written by nuns in Portugal in the seventeenth and eighteenth centuries. Special attention is given to the narrative of love, the description of ecstasies and extraordinary views. Based on the works of Michel de Certeau and Luisa Muraro on mystical writing, the aim is to understand the extent to which these texts by Portuguese female writers offer the possibility of thinking and articulating different discursive spaces so as to configure a discourse that embraces alterity.

KEYWORDS: Women's spiritual autobiographies; Portuguese baroque literature; spaces of alterity.

$\mathrm{A}$

centena de mulheres recenseadas com obra escrita em português nos séculos XVII e XVIII corresponde, na sua maioria, a monjas que escreveram desde tratados sobre a pedra filosofal, a obras de retórica e eloquência, até tratados de arquitectura, teologia ou filosofia, versando os mais diversos assuntos e explorando um amplo leque de géneros e formatos literários próprios da época: poesia lírica, épica, religiosa, teatro, prosa satírica, espiritual ou mística, crónicas, cartas, narrativa alegórica, pastoril, bizantina, etc ${ }^{1}$. No conjunto dessa produção escrita de autoria feminina as narrativas autobiográficas espirituais ocupam um lugar importante.

Este artigo propõe-se reflectir sobre a problemática da alteridade em algumas autobiografias espirituais femininas portuguesas do período barroco. Incide-se o foco de análise nas narrativas do eu amoroso e na descrição dos êxtases e visões extraordinárias que aqueles textos

\footnotetext{
${ }^{1}$ Vejam-se as autoras recenseadas nos seguintes dicionários e repertórios bibliográficos: Diogo Manuel Aires de Azevedo, Portugal Ilustrado pelo Sexo Feminino (1734); Damião de Froes Perim, Theatro Heroíno, (1740); Barbosa Machado, Biblioteca Lusitana, (1759); Inocêncio Francisco da Silva, Dicionário Bibliográfico Português (1858).
}

UNED. REI, 3 (2015), pp. 81-100 comportam. Partindo das sugestões de $\mathrm{M}$. de Certeau ${ }^{2}$ retomadas e desenvolvidas por Luce Irigaray ${ }^{3}$ e Luisa Muraro nos seus trabalhos dedicados à escrita mística, trata-se de perceber até que ponto essas autobiografias espirituais femininas oferecem a possibilidade de pensar espaços discursivos outros, configurando um discurso de alteridade, que em certa medida vai ao encontro do conceito que Bahba (1994) chamou de "third space". Isto é, o conceito de espaço discursivo híbrido, ambivalente, "lugar entre" que dissolve as fronteiras e os lugares rigidamente e essencialmente marcados. Solidamente enquadrados nos parâmetros ideológicos contrarreformistas, estes textos introduzem pequenas fissuras no edifício logocêntrico da metafísica de raiz platónica e aristotélica, ao pulverizar a fixidez monolítica das suas dicotomias-base: intelegível/sensível, natural/sobrenatural, corpo/espírito, dessa forma se constituindo como abertura para outras formas de racionalidades.

Evitando as leituras anacrónicas e cientes da importância de repor as obras no seu horizonte de recepção, pensamos no entanto, também com Certeau, que a leitura é apropriação e uma forma de habitar o escrito, razão pela qual se valoriza uma abordagem hermenêutica e multiperspética destes textos.

Por uma questão de método, fixamo-nos num conjunto limitado de textos, dois deles manuscritos, que cobrem o arco temporal do

${ }^{2}$ Na sua obra seminal, La Fable Mystique (Certeau, 1987:196-204), o estudioso sublinha a importância da linguagem no processo místico, apontando a relevância da forma de dizer nessa linguagem do outro, do inefável que é o discurso místico. A experiência é indissociável do texto e sua linguagem. Certeau levanta também a questão do sujeito nessa nova linguagem dos excluídos nos séculos XVI e XVII. Não correspondendo rigorosamente a textos de natureza mística, as narrativas de que nos ocupamos partilham contudo com o discurso místico momentos de comunhão extáctica com a divindade.

${ }^{3}$ A filósofa Luce Irigaray vê no discurso místico, histérico, misterioso, que designa como "mysterique" uma das formas de expressão da subjectividade feminina num contexto patriarcal. A seu ver, na história Ocidental o discurso místico é o lugar onde a mulher fala e age publicamente (Irigaray, 1974, 2009). Numa outra perspectiva, Hollywood (2002) consagra também a ligação entre o discurso místico e a subjectividade feminina.

UNED. REI, 3 (2015), pp. 81-100

ISSN 2340-9029 
período barroco em Portugal: "Relação da Vida da Madre Maria de S. José", da autoria desta religiosa Carmelita descalça (Maria de S. José, s.d.); "Cadernos", da Madre Mariana da Purificação (s.d.); a "Relação Fiel e Verdadeira que dá dos Sucessos de sua Vida a Criatura mais ingrata a seu Criador", de Soror Clara do Santíssimo Sacramento (1685), atualmente mais conhecida pelo nome secular de Antónia Margarida de Castelo Branco, e por fim a Vida da Serva de Deus Soror Isabel do Menino Jesus, a única obra deste conjunto impressa na época, da autoria daquela freira franciscana do Convento de Santa Clara de Portalegre (Isabel do Menino Jesus, 1752).

Façamos uma brevíssima apresentação das Autoras.

A Madre Maria de S. José, a mais enigmática deste conjunto, terá sido uma freira carmelita descalça que escreveu fragmentos da sua vida, numa fase terminal, quando se encontrava doente, por obediência ao confessor Frei Félix de Jesus. Segundo informação de João Palma-Ferreira (Branco: 33) terá professado no Convento do Santíssimo Sacramento de Lisboa em 1634. Quanto à Carmelita Madre Mariana da Purificação (1623-1695), sabe-se que professou no Convento da Esperança de Beja em 1663, onde permaneceu até à morte. Ainda hoje é objecto de veneração na cidade de Beja. A sua vida foi pontuada por práticas de mortificação, visões, actos de comunhão com a divindade. Denunciada à Inquisição de Évora como falsa mística, foi objecto de dois exames - um em 1669 e outro em 1670 - tendo o seu processo sido arquivado como inconclusivo em 27 de Setembro de 16724. Antónia Margarida de Castelo Branco, que viveu entre 1652 e 1717, foi filha de António de Albuquerque, capitão-mor e governador do Maranhão e Paraíba e de Joana Luisa Castelo Branco. Na sequência de uma atribulada vida conjugal de que dá conta na Relação, conseguida a anulação do casamento, esta mãe de família professou no Convento da Madre de Deus de Xabregas de Lisboa, com o nome de Soror Clara do Santíssimo Sacramento. O manuscrito que escreveu

${ }^{4}$ Para um conhecimento aturado da vida desta freira vejam-se as biografias de Fr. Caetano do Vencimento (1747) e de Frei Miguel de Azevedo (1802). Ver também a nossa síntese em Couto (2006: 33-41)

UNED. REI, 3 (2015), pp. 81-100 por obediência aos padres espirituais que a foram acompanhando ao longo da sua tormentosa vida, e do qual se encontram várias cópias manuscritas, foi objecto de uma edição contemporânea a cargo de João Palma-Ferreira (Branco, 1983) com o título Autobiografia. Por último, a Franciscana Soror Isabel do Menino Jesus (1673-1752) foi religiosa do Mosteiro de Santa Clara de Portalegre. Proveniente de uma família de proprietários rurais, governou a casa dos pais até aos 35 anos, altura em que entrou no Mosteiro. Desenvolveu um método de oração mental. Em 1737, aos 64 anos, ainda se ocupava na redacção de cartas de orientação e conforto espiritual para a comunidade. Para além da história da sua vida, o livro contém um tratado místico com a descrição da via purgativa, unitiva e iluminativa. O volume inclui também um conjunto abundante de correspondência epistolar de conforto e direcção espiritual dirigido a religiosos e religiosas.

Enquadradas no campo mais vasto das biografias de religiosos e das hagiografias, as narrativas autobiográficas de autoria feminina são um tipo de narrativa que em Portugal se difundiu ao longo do século XVI e atingiu o seu auge nos séculos XVII e XVIII ${ }^{5}$. Geralmente intitulam-se "Relação de vida", ou "Vida da Serva de Deus". A quase totalidade destes textos corresponde a manuscritos que circularam nos conventos. Impresso na época, conhece-se o já referido livro de Soror Isabel do Menino Jesus, Vida Serva de Deus Soror Isabel do Menino Jesus, publicado postumamente em Lisboa em $1757^{\circ}$.

${ }^{5}$ A este propósito veja-se o estudo de Mendes (2013).

${ }^{6}$ Não existem ainda estudos de conjunto suficientemente amplos e estudos parcelares exaustivos sobre as autobiografias femininas de língua portuguesa do período barroco que permitam traçar com minúcia e certeza o quadro e a especificidade dessa produção no contexto mais vasto da produção hispânica e europeia com a qual partilha obviamente um conjunto de constantes. Sem pretender ser exaustiva, destacamos no que respeita a estudos de levantamento e de enquadramento conceptual: Palma-Ferreira (1983); Cunha (1992); Belo (1993); Morujão (1995, 2011); Villas-Boas Tavares (1996); Couto (2002; 2007; 2009); Santos (2002); Bellini (2006); Anastácio (2013). No que respeita a estudos de carácter monográfico vejam-se os estudos de Milheiro (2004); Duque (2013); Serrado (2014). Para um enquadramento geral do tema no contexto hispânico vejam-se os trabalhos de fôlego de Poutrin (1995), Herpoel (1999), Durán (2007) e Ferrús (2004).

UNED. REI, 3 (2015), pp. 81-100

ISSN 2340-9029 
Enquanto exercício espiritual, a autobiografia tal como se praticou em seiscentos e setecentos, tem amplas raízes na tradição cristã, remontando às Confissões de Santo Agostinho e à tradição medieval das «vidas de santos», culminando no século XVI com os textos autobiográficos de San Ignacio de Loyola e Santa Teresa de Ávila?

Com uma função exemplar e edificante muito nítida ${ }^{8}$, estes textos enquadram-se no contexto de exaltação do santo como herói, tal como a Contrarreforma Católica a difundiu e no quadro da promoção que as ordens religiosas neste período fizeram das suas freiras exemplares. Reproduzindo o ideal da imitação da perfeição de Cristo, as biografias espirituais reflectem os modelos ideais dos santos recém-canonizados: Santo Inácio de Loiola e Santa Teresa9. Estes textos articulam-se com uma prática confessional que se levou a cabo nos conventos, cujo objectivo era formar os religiosos e que posteriormente entraria na vida civil. Neste contexto, as autobiografias femininas cumpriram a exigência não só de fornecer modelos de comportamento, como de moldar e apaziguar as consciências das freiras. A este propósito, convém lembrar que, independentemente da maior ou menor proximidade e afinidade espiritual que unia freira e confessor, este tipo de escrita autobiográfica era frequentemente solicitada pelo confessor ou director espiritual às religiosas e em especial às místicas e visionárias, aquelas que se destacavam por receber favores

\footnotetext{
${ }^{7}$ Para uma história da autobiografia espiritual em geral veja-se Vernet (1937).

8 Tal como a generalidade dos estudiosos da matéria, Bruss em "l’Autobiographie considerée comme acte littéraire" (1974) sublinha a finalidade didáctica e exemplar como um dos traços genéricos das autobiografias religiosas.

${ }^{9}$ O carácter modelar da Vida de S. Teresa e o fenómeno do mimetismo das suas visões é enquadrado por Eulogio Pacho (1969). Também Poutrin (1995: 76-87) sublinha o caráter modelizador do Libro de la Vida nas narrativas autobiográficas, que de resto é bem visível nas autobiografias portuguesas. A estudiosa aponta também a influência da Mística Ciudad de Maria de Ágreda, que segundo nos parece estará presente em Soror Isabel do Menino Jesus e nas suas viagens imaginárias pelo mundo, e ainda de Soror Juana Inés de la Cruz, cuja relação com a produção literária conventual portuguesa é de grande proximidade.
}

ou mercês e que por essa razão mais se afastavam dos regulamentos e prescrições normativas ${ }^{10}$.

Ler um texto desta natureza é perceber que estamos perante uma classe de textos particular na história da autobiografia: textos escritos a pedido, com uma função exemplar e edificante muito clara, obedecendo a um conjunto preciso de parâmetros narrativos.

Com efeito, "As relações de vida" frequentemente apresentam uma estrutura similar, seguindo um conjunto de topoi e de características que se repetem, tal como confirma Cunha (1992).

Exceptuando o texto da Madre Maria de São José, os demais textos estudados não fogem à regra. Descrevendo o percurso individual das religiosas antes e depois da entrada no convento, quase sempre começam com a referência ao nascimento e uma breve passagem pela infância. Segue-se o "chamamento" —o despertar da vocação- e uma revisitação de vários episódios da vida em função de valores como os de expiação e redenção: acontecimentos, acções, pensamentos, sentimentos, tentações, sonhos, visões, são dissecados e reenquadrados como formas de aproximação a Deus. A este propósito convém lembrar com Vernet (1937) que a autobiografia espiritual é sempre em certa medida uma narrativa de conversão que permite passar de um cristianismo incompleto a um mais ferveroso.

Apesar de obedecerem a estritas convenções, algumas destas narrativas revelam-se como inesperadas peças literárias: será o caso do texto da Madre Maria de São José ou de Antónia Margarida de Castelo Branco.

Relatando episódios da vida quotidiana das religiosas, exprimindo os seus sentimentos e conflitos interiores, os seus êxtases ou visões proféticas, estes textos ganham uma tonalidade única pela dimensão de experiência privada que transportam consigo. A par de documentos de época fornecendo dados sobre a vida conventual, educação,

${ }^{10}$ Veja-se a este propósito o acompanhamento e apoio de Frei António de Escobar às manifestações místicas de Madre Mariana da Purificação, que lhe valeram o afastamento do cargo de confessor (Couto, 2006).

UNED. REI, 3 (2015), pp. 81-100

ISSN 2340-9029 
sociablidade etc., as "relações de vida" poderão igualmente ser vistas como uma espécie de documentos do desejo e exercícios de construção de subjectividades.

É certo que o eu autobiográfico ali representado é em certa medida uma convenção, uma personagem exemplar construída a partir de determinados parâmetros literários e religiosos, mas simultaneamente esse eu é também uma personagem onde ecoa a singularidade, aquilo que Caravero (2007) define como o que existe de único e irrepetível no sujeito. Apesar de cumprirem um programa específico estes textos são também, formas importantes de construção de subjectividades ${ }^{11}$.

Poder-se-á dizer que nas narrativas que estudámos, o eu autobiográfico é constantemente atravessado pela tensão entre o convencional e o singular, entre a memória (com tudo o que implica de construção) e a ficção. Nas entrelinhas é possível aceder aos interstícios de uma intimidade tecida de silêncios, de espaços em branco, de insinuações, onde as ausências pesam tanto como as próprias palavras. Nessa mescla de palavras e ausências irrompe a singularidade única e irrepetível do eu. É nessa ambiguidade estrutural que residirá em parte o interesse desta classe de textos, onde o sujeito de enunciação é constantemente atravessado pela tensão entre o modelar e o singular, entre a ficção e a realidade, entre o dito e o não dito.

No que respeita à história das mulheres, através deles lemos o estigma de inferioridade que o sexo feminino trazia consigo à nascença, a situação de sujeição legal das mulheres, as opções de vida —casamento ou claustro- que se colocavam às mulheres de posição social elevada, os métodos de educação de uma elite letrada.

Da vida conventual sobressai a valorização social do modelo das veneráveis, o clima de espriritualidade devota, a vigilância e controle às manifestação místicas, as festividades religiosas e as redes de ligação social ao mundo secular.

${ }^{11}$ No caso da literatura hispânica, Arenal e Schlau vêem nesta escrita um forte signo de afirmação de si (Arenal, 1989:15).

UNED. REI, 3 (2015), pp. 81-100
As autobiografias oferecem ao leitor o quotidiano, as rotinas, as tarefas, o pequeno e o grande acontecimento da vida conventual (por exemplo, o alarido em torno do roubo de uns castiçais, ou a chegada de um novo confessor). Nelas se plasmam os jogos de relações, os afectos, as amizades, os ciúmes, as pequenas hostilidades, "os murmúrios". A par da intensidade do fervor religioso, ali afloram os dramas íntimos, as saudades do passado, o apelo da vida exterior ao Convento, ou a dureza do processo de escrita. Emerge a dúvida e o peso do sentimento do pecado. A batalha contra as tentações carnais é uma constante, frequentemente expressa através do apelo do demónio:

A este propósito, atente-se nas palavras de Antónia Margarida de Castelo Branco:

Na semana passada tive terceiro assalto contra a obediência. Havia alguns meses que tinham crescido as murmurações com as minhas detenças no confessionário. [...] Em Fevereiro do ano seguinte de 87 se tornou a turbar o meu interior com várias tribulações que me traziam quase irracional [...] O demónio atormentava-me com imaginações de que jogava comigo como com arma sua. Algumas horas senti veementes impulsos de desesperar e de outros vícios. (Branco, 1983: 363)

Sobressai a tentativa de praticar as virtudes — modéstia, obediência, a renúncia ao amor-próprio ("em cinco anos antes de entrar para o Convento me não vi em espelho" diz Soror Isabel do Menino Jesus) - , bem como as mortificações. A este propósito, refere a Madre Maria de São José:

No que toca à penitência tive sempre grandes desejos dela, posto que nunca chegaram minhas obras a meus desejos. Procurava licença das Preladas, e às vezes dos Prelados, e davam-me algumas para tomar disciplina e usar de cilícios e cadeias alguns dias da semana, e alguns jejuns de pão e água em dias particulares [...] como em vésperas de Nossa Senhora e de Nosso Senhor, e na Quaresma somente me concediam as sextas-feiras. (Maria de São José, s.d.: fl.273)

UNED. REI, 3 (2015), pp. 81-100

ISSN 2340-9029 
Mas esses textos falam também das delícias do amor divino, das mercês, da união com a divindade, apresentando ao leitor as visões extraordinárias que se associam a esses momentos. Ali afloram as visões e a desregulação dos sentidos. A procura do êxtase. As delícias e tormentos do amor místico: explosão dramática de alegria física e espiritual, na sua máxima exuberância.

Interessa neste artigo realçar a estética e a retórica de entrega e júbilo que em parte também caracteriza estes textos. É com grande enlevo que a carmelita madre Maria de São José, por exemplo, relata uma das múltiplas visões extraordinárias que preenchem o seu manuscrito:

Estando uma noite no coro em oração, me mostra Cristo um campo de flores mui ameno, e de alegre vista, onde sua Divina Majestade estava sentado, com mui grande formosura, e em particular lhe vi as mãos, com toda e muito mais perfeição que a esposa nos Cantares. Das mais perfeições do rosto não pude dar fé. Em alguns dos dedos tinha anéis formosísimos de ouro e pedras a modo de safiras, mas não têm que ver as cousas deste lugar mui pobre e miserável em que vivemos com aquelas. Estas bem ditas mãos que digo estavam todas rodeadas de um orvalho fresquíssimo, e branquíssimo, a modo de aljôfar grande, mas de bem diferente formosura (Maria de São José, s.d.: fl.270)

São visões inefáveis, esplenderosas, saturadas de perfeição, beleza, luz, cor, brilho, onde ecoa a intensidade do imaginário de recorte bíblico $^{12}$.

12 Elucidando o contexto que presidia à emergência das visões extraordinárias, Niccoli (2011:9-21) descreve as diferentes práticas de visualização que faziam parte da vida conventual: a leitura da Bíblia com o seu apelo à visão, as miniaturas representando as vidas de santos e de Cristo, objeto de meditação e conforto, os exercícios de composição visual a partir das práticas de meditação divulgadas por Santo Inácio de Loiola. A ideia de fisicalidade, de proximidade física do além temporal estava também presente nos atos de culto, em que beijar, saudar as imagens religiosas era comum. A estes aspetos convém acrescentar toda a dimensão intensamente visual da cultura barroca o ponere ante óculos, e essa loucura do ver de que fala Buci-Gluksman em La folie du voir.
Percebidas com os olhos do corpo, do espírito e da alma, estas visões sugerem uma outra forma de percepção consubstanciada na expressão de "ver com o coração":

Outra noite na mesma hora que acima digo antes de tangerem as matinas, estando eu no coro, bem apertada na oração, senti junto a mi um anjo de pequena estatura e grande formosura e alegria de dentro e tão ágil e ligeiro que me lembrou com quanta razão o Profeta chama aos anjos ministros de fogo. Trazia na mão um molho de setas; Com algumas me trespassava o coração, lançando trás uma e outra com grande pressa, de sorte que, quando tangiam a matinas, com grande trabalho estive nelas e não sei se entendi o que rezava, porque desejava a alma não sair daquele exercício amoroso. (Maria de São José, s.d.: fl.279)

Convocando um lugar indefinido, híbrido, apelando a uma indistinção corpo-espírito alheia à metafísica de raiz platónica, estas descrições sugerem um espaço refractário à postura mais abstracta e racional da cultura teológica. Sugerindo uma outra forma de perceber, de conhecer, de dizer, apontam uma outra articulação discursiva. Conforme as citações acima esclarecem, trata-se de uma articulação discursiva que privilegia o lugar-entre e escapa à lógica da organização simbólica do mundo assente numa visão dicotómica da realidade, que sutenta os dualismos intelegível-sensível, corpo-espírito, material/espiritual, natural/sobrenatural, etc.

Efectivamente, as experiências e visões místicas são descritas como um arrebatamento simultaneamente físico e espiritual, como uma espécie de deslocação espacio-temporal, frequentemente expressa em termos de "rapto" e de "transporte". Palavras como suspensão, elevação, voo, sucedem-se para expressar esse movimento imperioso, inexplicável que num ápice arrebata o eu e o atira para fora de si. "Absortas" durante horas, o corpo destas veneráveis fica "como que morto", enquanto se deixam arrebatar por uma felicidade corporalmente espiritual nos braços amáveis do seu doce Esposo. 
Diz Soror Isabel do Menino Jesus:

Uma noite destas, acabada a obrigação de Matinas [...] me pus em oração, [...] Imediatamente me cercou uma grande luz, que bastou para ficarem logo as potências (faculdades) alienadas e presas a Deus. E estando assim algum tempo, me achei sem saber como, toda coberta de ouro fino, que a meu entender, me parecia que corpo e alma estava vestida de ouro [...] Saí em suspensão, ficando sem sentidos, nem potências. (Isabel do Menino Jesus, 1757: 215).

E noutra ocasião, utilizando uma expressão curiosa que apaga a clivagem corpo/espírito: "Aqui conheci claramente, com inteligência espiritual e corporal, que quase se me representou (Cristo) com sua santíssima humanidade." (Isabel do Menino Jesus, 1757: 55).

Estas manifestações irrompem, por vezes, no quotidiano do convento inadvertidamente perturbando o seu frágil equilíbio. Trata-se de um espaço de liberdade e comunhão que desabrocha de súbito no interior da clausura, jardim murado, que o convento é, com seu sistema de barreiras e grades. Como se sabe, a Contrarreforma em Portugal vigiou o êxtase, em particular das religiosas, com o fito de demarcar nitidamente as manifestações místicas de eventuais práticas heréticas. A Madre Mariana da Purificação foi uma das que foi acusada de falsa mística, tendo sido objecto de dois processos inquisitoriais. A ambiguidade das suas manifestações à luz do Santo Ofício está patente nas declarações de um dos comissários do Tribunal da Inquisição: “...me pareceram suas revelações falsas como embustes seus, ou enganos do inimigo e nelas alguns ditos ou proposições malsoantes, escandalosas, temerárias, erróneas, ou heréticas" (Inquisição de Lisboa: fl. 238). Também as manifestações de Soror Isabel do Menino Jesus foram objecto de alguma vigilância, embora tenha vindo a ser considerada uma autoridade mística.

Estes textos revelam-nos sujeitos que exploram os meandros da palavra e do amor, que saem de si e experimentam a fusão com o "uno": experiências íntimas, intrinsecamente paradoxais que afron-

tam a ordem do conhecido. É com grande despojamento que esta Franciscana dá conta dos seus êxtases, não escondendo do leitor a perturbação íntima que tal exposição ao desconhecido acarreta, especialmente quando traz a marca do feminino. Diz, a dada altura no seu livro: "O caminho da via unitiva é caminho sem carreira e não se anda por ele senão por voos; e por voar tão alto, que vai fora da capacidade de mulher, confesso que temi o voar, com receios de cair de tão alto." (Isabel do Menino Jesus, 1752: 149). Trata-se de uma entrega que implica sentimentos como o incómodo, conforme aponta Mariana da Purificação:

Sucedeu-me já há algum tempo, que estando no Coro, Nosso Senhor fez-me mercê de me unir consigo; amanhecendo, indo gente para o Coro, me acharam assim. Coisa que eu senti muito, porque logo vieram umas e outras, e fizeram uma roda à volta de mim. Quando acordei fiquei tão corrida e envergonhada que não quisera aparecer diante de gente e por isso desejo sempre andar metida pelos cantos. (Mariana da Purificação, s.d.: fl. 272)

O relato dos transportes místicos revela uma atitude de entrega e de abertura à alteridade, ao outro amoroso. No seu livro Il Dio delle Donne, dedicado à escrita mística feminina, Luísa Muraro sublinha o facto de estes textos falarem de uma experiência de relação: o eu está em relação com um outro para além de si. Efectivamente, as narrativas dos êxtases exprimem uma receptividade extrema a esse outro -o objecto amado. Esses relatos colocam-nos perante sujeitos que desejam ser afectados pela "outridade": "Assim como o sal se desfaz na água e fica todo incorporado nela, se desfazia minha alma para incorporar-se com Deus" diz Antónia Margarida de Castelo Branco (1983: 266). Também as palavras de Sóror Isabel do Menino Jesus vão na mesma direcção:

Estando em uma ocasião em Oração, ouvi umas palavras, que diziam: Esposa abre-me as portas do teu coração. Foram as palavras tão poderosas, que com a ternura delas, me levaram logo os afectos, que por muito espaço de tempo

UNED. REI, 3 (2015), pp. 81-100

ISSN 2340-9029 
não soube de mim; e cobrando alguma inteligência, entendi que minha alma se transformava em Deus..." (Isabel do Menino Jesus, 1752: 16)

O amor é vivido como um percurso que culmina no eu diluindo-se no amor divino. As metáforas da abertura, da oferta, da dádiva sucedem-se para dar conta da experiência inefával da união com o amado. Estamos longe do sujeito autónomo, fechado sobre si mesmo da tradição Ocidental.

A veemência dos transportes amorosos e das visões extraordinárias impõem-se numa escrita em que o gozo impera. Esse lugar a que se acede imprevistamente, como uma dádiva, constitui o reino da felicidade, assento da experiência jubilosa do amor. Nesta retórica do júbilo sucedem-se as expressões que dão conta da felicidade da união: consolo, favores, glória, delícias, gozo: "Estava tão fora de mim com o júbilo que gozava minha alma, que não podia tomar assento o discurso", (Isabel do Menino Jesus, 1752: 17) afirma Soror Isabel do Menino Jesus, e Antónia Margarida de Castelo Branco: "Sempre nestes incêndios sentia grande regalo e sossego interior" (Branco, 1983: 246)

Experimentando o outro, o inefável, o indizível, trata-se de encontrar uma outra forma de dizer, o que, de resto, tem sido amplamente apontado pela generalidade dos estudiosos do discurso místico. Nessa busca da fala amorosa o jogo de metáforas sucede-se, exibindo essa "sintaxe do fogo" que atravessa a generalidade dos relatos místicos, nessa tentativa de superar os limites da linguagem para dizer o que não pode ser dito, ou compreendido:

A forma ordinária destes toques eram por aquele sentimento de fogo no coração que algumas vezes crescia com os actos; outras era uma seta já formada que em me penetrando me deixava ardendo. Sempre começava pelo coração e daí se comunicava ao interior e todos seus efeitos eram puríssimos. O coração sentia então grandes palpitações, mas sem aflição nem desassossego, antes me serviam de regalo. (Branco, 1983: 245)
Nesta procura de uma outra linguagem a inscrição do corpo na escrita é uma constante ${ }^{13}$ :

E estando assim me adormeci ao peito do meu doce e amado esposo. Lançou o senhor o seu braço que estava tão magestoso e me apertou muito a si. O que então ali logrou minha alma, não o sei compreender, e muito menos dizer, nem dar a mínima noticia. (Mariana da Purificação, s.d.: fl.272)

O corpo é usado como forma de comunicar, seja através do recurso a imagens saturadas de erotismo, em harmonina com a mística nupcial e a longa tradição que remonta ao "Cântico dos Cânticos", como no caso anterior, seja através do recurso às imagens da doçura do amor maternal, centrada na figura de Jesus Menino:

Um dia estando na cela [...] deu-me um ímpeto de amor tão forte, que me suspendeu. Em todo este tempo estive logrando grandes favores e carícias do Menino. [...] Nesta ocasião se me veio pôr no colo com um ramalhete de boninas brancas e se pôs a brincar comigo: Dava-mas e tornava-mas a tirar, e dava-mas a cheirar, e outras muitas garridices. (Mariana da Purificação, s.d.: fl.272)

A inscrição dos sentidos, a sinestesia é também uma constante nestas narrativas. Reportando-se a um colóquio com a divindade, Sóror Isabel do Menino Jesus refere, a dada altura: “Traziam estas palavras grandíssima eficácia, com muita doçura e fragrância de cheiro suavíssimo" (Isabel do Menino Jesus, 1752: 55).

Também o recurso ao grito inarticulado, aos gemidos, aos suspiros, é outra forma de dizer o que não pode ser dito por palavras e de inscrever o corpo na demanda por essa outra forma de linguagem.

Em suma, penso que ficou claro que no espaço fechado, ordenado do convento, o relato das visões e manifestações, ainda que não in-

\footnotetext{
${ }^{13}$ A expressão é de Helène de Cixous informando o conceito de "écriture féminin" (Cixous, 2010: 17).
}

UNED. REI, 3 (2015), pp. 81-100

ISSN 2340-9029 
tencionalmente, acaba por criar um espaço híbrido de abertura, um espaço relacional, que implica quebra de fronteiras e categorias.

Neste sentido, esses relatos aproximam-se do conceito de "pequenas astúcias do quotidiano" que Certeau utiliza para designar os pequenos gestos de subversão a que certas práticas do fazer correspondem. Na obra L'invention du quotidien Michel de Certeau analisa as práticas quotidianas - falas, gestos, movimentos das massas anónimas - detetando pequenos desvios da norma, que proliferam no interior das estruturas do sistema. Ainda que sem confronto direto aos poderes sociais, estes pequenos gestos acabam por criar uma resistência, revelando uma apropriação do espaço social resignificando-o.

É a esta luz que podem também ser compreendidas as visões e êxtases das narrativas autobiográficas: operações de micro-resistência compondo uma "rede de antidisciplina" que esvazia as pretensões de uniformização abrindo-se à alteridade.

Desenhando um espaço de enunciação híbrido os relatos de visões e êxtases podem, finalmente, ser vistos como espaços de resistência e abertura para outras cartografias discursivas e outras formas possíveis de habitar o mundo.

Recibido: $13 / 06 / 2015$

Aceptado: 09/08/2015

\section{Referências bibliográficas}

Anastácio, Vanda et al. (2013), Uma antologia Improvável. A Escrita das Mulheres (1495-1830), Lisboa: Relógio d’Água.

Arenal, Electa e Stacey Schlau (1989), Untold Sisters. Hispanic Nuns in their Own Works, Albuquerque: University of New Mexico Press.

Azevedo, Diogo Manuel Aires de (1734), Portugal Ilustrado pelo Sexo Feminino, Lisboa.
Azevedo, Miguel de (1802), Memorial das Instrutivas Palavras e Edificantes Obras da Muito Virtuosa Madre Mariana da Purificação, Lisboa: Oficina de Simão Tadeo Ferreira.

Bellini, Lígia, (2006), "Vida Monástica e práticas de escrita entre mulheres em Portugal e no Antigo Regime", Campus Social, 3 / 4, pp. 209-218.

Belo, Maria Filomena (1993), Relação da vida e morte da serva de Deos a Veneravel Madre Elenna da Cruz, por Sóror Maria do Céu, Lisboa: Quimera Editores.

Bhabha, Homi K. (1994), The Location of Culture, London: Routledge.

Branco, Antónia Margarida de Castelo (1983), Autobiografia, João Palma-Ferreira ed., Lisboa: Imprensa Nacional-Casa da Moeda.

Bruss, Elizabeth (1974), "l’Autobiographie considerée comme acte littéraire”, Poétique, 17, pp.14-18.

Buci-Gluksman, Christine (1986), La folie du voir: De l'esthétique baroque, Paris: Editions Galilée.

Caetano do Vencimento (1747), Fragmentos da prodigiosa Vida da muito favorecida e amada Esposa de Jesus Cristo, a Veneravel Madre Mariana da Purificação, Lisboa: Oficina de António da Silva.

Cavarero, Adriana (2007), Tu che mi Guardi, tu che mi Racconti: Filosofia della Narrazione, Milano: Giagcomo Feltrinelli Editore.

Certeau, Michel de (1987), La fable mystique 1.XVI ${ }^{e}$-XVII siècles, $\mathrm{Pa}$ ris: Gallimard.

--- (1990), L'invention du quotidien, t. I: Arts de faire, Paris: Gallimard.

Couto, Anabela Galhardo (2002), "Escritoras de finais do século XVII e inícios do século XVIII: seu contributo para a definição de uma cultura barroca em Portugal", em Maria Helena Alvim, Anne Cova e Elvira Mea eds., Em Torno da História das Mulheres, Lisboa: Universidade Aberta, pp.193-206. 
--- (2003 ), "Literatura de autoria feminina: Um património da palavra a reinventar" em Zília Osório de Castro dir., Falar de Mulheres: Da Igualdade à Paridade. Lisboa: Livros Horizonte, pp. 43-53.

--- ( 2006), Uma Arte de Amar: Ensaio para uma Cartografia Amoro$s a$, Lisboa:101 Noites.

--- (2007), Gli Abiti Neri: Letteratura femminile del Barocco Portoghese, Roma: Il Filo.

--- et al., (2009), Teaching subjectivity: Travelling Selves for Feminist Pedagogy, Utrecht: Utrecht University/Athena.

Cixous, Hélène de (2010), Le Rire de La Méduse et autres ironies, Paris: Éditions Galilée.

Clara do Santíssimo Sacramento (1685), Relação Fiel e Verdadeira que dá dos Sucessos de sua Vida a Criatura mais ingrata a seu Criador, Por obediência de seus Padres Espirituais e novamente tornada a escrever por um sucesso na era de 1685 annos, manuscrito da BNP, cod.538.

Cunha, Mafalda Ma Ferin (1992), “A Fiel e Verdadeyra relação que dá dos sucessos de sua vida a criatura mais ingrata a seu criador: um género, um texto único", Dissertação de Mestrado em Literatura e Cultura Portuguesas, Lisboa: Universidade Nova de Lisboa.

Duque, José Félix (2013), “Sóror Isabel do Menino Jesus por Michele Bouteux: o retrato de uma venerável escritora", Revista Invenire, 3, pp. 28-33.

Durán López, Fernando (2007), Un cielo abreviado: Introducción crítica a una historia de la autobiografía religiosa en España, Madrid: FUE/Universidad Pontificia de Salamanca.

Ferrús Antón, Beatriz (2004), Discursos cautivos: vida, escritura, convento, València: Universitat de València.

Herpoel, Sonja (1999), A la zaga de Santa Teresa: Autobiografias por Mandato, Amsterdam/ Atalanta: Editions Rodopi.

Hollywood, Amy (2002), Sensible ecstasy. Mysticism, Sexual Difference and the Demands of History, Religion and Postmodernism, Chicago: University Chicago Press.
Inquisição de Lisboa: M.s. nº 1720 da Torre do Tombo de Lisboa. Irigaray, Luce (1974), Speculum de l'autre femme, Paris: Éditions de Minuit.

--- (2009), “Toward a Divine in the Feminine" em Gillian Howie ed., Women and the divine: touching transcendence, NY: Palgrave Macmillan, pp. 13-26.

Isabel do Menino Jesus (1752), Vida da Serva de Deus Soror Isabel do Menino Jesus, Lisboa: Oficina de José da Costa Coimbra.

Maria de S. José (s.d.), Relação da Vida da Madre Maria de S. José religiosa Carmelita descalça, Manuscrito da Biblioteca Nacional Portugal, Cod.79. fl. 264-283.

Mariana da Purificação (s.d.), Cadernos, Manuscrito da Torre do Tombo de Lisboa. N.D., Inquisição de Lisboa, m.s. 1720.

Mendes, Paula Cristina Almeida (2013), Porque aqui se vem retratados os passos por onde se caminha para o Ceo: a escrita e a edição de 'Vidas' de santos e de 'Vidas' devotas em Portugal (séculos XVI-XVIII), Tese de Doutoramento, Universidade do Porto (Texto policopiado).

Milheiro, Dalila (2004), Dimensões do feminino na "Fiel e verdadeira Relação de Clara do Santíssimo Sacramento", Dissertação de Mestrado em Estudos sobre as Mulheres, Lisboa: Universidade Aberta de Lisboa (Texto policopiado).

Machado, Barbosa (1759), Biblioteca Lusitana, Lisboa: Luiz Ameno.

Morujão, Isabel (1995), Contributo para uma bibliografia cronológica da literatura monástica feminina portuguesa dos séculos XVII e XVIII: impressos. Lisboa: Universidade Católica Portuguesa, Centro de Estudos de História Religiosa.

--- (2011), "Entre a voz e o silêncio: literatura e espiritualidade nos conventos femininos", Rever, 11, n ${ }^{\circ}$, Jan/Junho, pp. 35-54.

Muraro, Luisa (2003), Il Dio delle donne, Milano: Mondadori.

Niccoli, Ottavia (2011), Vedere con gli ochi del cuore: Ale origini del potere dele immagini, Roma-Bari: Editorial Laterza.

UNED. REI, 3 (2015), pp. 81-100

ISSN 2340-9029 
Pacho, Eulogio (1969), "Literatura espiritual del barroco y de la ilustración", em Baldomero Jiménez Duque e Luís Sala Balust dirs., Historia de la Espiritualidad, Barcelona: Juan Flors Editor, vol. II.

Palma-Ferreira, João, ed. (1983), Autobiografia, de Antónia Margarida de Castelo Branco, Lisboa: Imprensa Nacional-Casa da Moeda.

Perim, Damião de Froes (1740), Teatro Heroino, Abecedário Histórico e Catálogo das Mulheres Ilustres em Ciências e Artes Liberais, Lisboa: Régia Oficina Silviana.

Poutrin, Isabelle (1995), Le Voile et la Plume: Autobiographie et Sainteté Féminine dans l'Espagne Moderne, Madrid: Casa de Velázquez.

Roullet, Antoine (2015), Corps et Pénitence: Les Carmélites Déchaussés Espagnoles (1560-1640), Madrid: Casa de Vélazquez.

Santos, Zulmira C. (2002), "Hagiografia. A prosa religiosa e mística nos séculos XVII-XVIII", em História da Literatura Portuguesa, Vol. 3: Da época Barroca ao Pré-Romantismo, Lisboa: Alfa, pp. 165-169.

Serrado, Joana, (2014), Ancias/Anxiousness in Joana de Jesus: Historical and philosophical perspectives, Tese de Doutoramento, Universidade de Groningen.

Silva, Inocêncio Francisco da (1858), Dicionário Bibliográfico Português, Lisboa: Imprensa Nacional.

Tavares, Pedro Vilas Boas (1996), "Caminhos e Invenções da Santidade feminina”, Via Spiritus, 3, pp.163-215.

Vernet, F. (1937), "Autobiographies spirituelles", em Marcel Viller et al. eds., Dictionnaire de Spiritualité Ascétique et Mystique Doctrine et Histoire, Paris: Beauchesne, vol. 1, col. 1141- 1159. 